\title{
Rotordynamic Stability Case Studies
}

\author{
Pranabesh De Choudhury \\ Elliott Company, Jeannette, Pennsylvania, USA
}

In this article case studies are presented involving rotordynamic instability of modern high-speed turbomachinery relating the field data to analytical methods. The studies include oil seal related field problems, instability caused by aerodynamic cross-coupling in high-pressure, high-speed compressors, and hydrodynamic bearing instability resulting in subsynchronous vibration of a high-speed turbocharger. It has been shown that the analytical tools not only help in problem diagnostics, but also aid in problem resolution. Examples are presented showing how analytical methods, when appropriately applied, can solve rotordynamic instability and result in stable rotor system.

Keywords Bearings, Rotordynamics, Seals, Stability

The rotordynamic associated with modern turbomachinery needs to be addressed in more depth due to frequent operation speed of rotating machinery substantially above the first rigid support critical speed (De Choudhury, 2001). Moreover, modern high-speed turbomachineries operate at relatively high pressures and gas densities, resulting in rotor dynamics problems. It has been found that under certain conditions a rotor may precess about the bearing center at a speed below the operating speed. Such motion is termed as nonsynchronous, and is due to self-induced vibration (Newkirk and Lewis, 1956). Self-induced vibrations are caused by forces controlled by the motion itself as opposed to forced vibration which is a function of only time (Boeker and Sternlicht, 1956). Such whirling motion may be caused by external factors such as internal damping (Gunter, 1966), hydrodynamic forces in fixed geometry journal bearings (Reddi and Trumpler, 1962; Newkirk and Taylor, 1925), or oil seals (Kirk and Miller, 1979). Aerodynamic forces can also cause self-induced vibration in axial compressors and turbines

Received 30 March 2003; accepted 30 June 2003.

Address correspondence to Pranabesh De Choudhury, Elliott Company, 901 North Fourth Street, Jeannette, PA 15644, USA. E-mail: pdech@elliott-turbo.com

(Alford, 1965) as well as centrifugal compressors (Wachel, 1982; Sood, 1979). Subsynchronous vibration in centrifugal compressors may occur in high gas pressures and gas densities applications beyond certain operating conditions and speeds.

In this article, three case studies are presented related to stability problems associated with high-speed turbomachinery. Each case is associated with a different aspect of rotordynamic stability. The use of available analytical tools in problem diagnostics are also presented, leading to problem resolution. Vibration data related to the cases have also been included, where available.

\section{DISCUSSION OF ANALYTICAL METHODS}

The stability of motion is determined by observing the motion of the linear system after giving it a small perturbation about an equilibrium position. If this motion dies out with time and the system returns to its original position, the system is said to be stable; on the other hand, if this motion grows with time, it is said to be unstable.

To test for stability of a rotor-bearing system, the homogeneous equations of motion are solved. If the coefficients of these differential equations are constants, their solutions consist of linear combinations of exponentials (Poritsky), $e^{\lambda_{1} t}, e^{\lambda_{2} t}, \ldots e^{\lambda_{n} t}$, where the $\lambda$ 's are the roots of the characteristics equation:

$$
\sum_{k=0}^{n} A_{n-k} \cdot \lambda^{k}=0
$$

Equation (1) can be solved to obtain the root, $\lambda$, which is usually complex and of the form

$$
\lambda=P+i \cdot \omega_{d}
$$

The real part of the root, $P$, predicts the decay or growth rate of motion of the system. If $P$ is negative, the system is stable since the motion decays with time. If $P$ is positive, the system is unstable. For $P=0$, the system is on the threshold of stability, i.e., the parameters controlling the system keep it neutrally stable and when they are changed the system may go into either a stable or unstable region. The frequency $\omega_{d}$ represents the damped natural frequency of the system.

Before the advent of high-speed computers and supporting mathematical algorithms for manipulating complex numbers, 
it was virtually impossible to solve for the damped eigenvalues associated with multi-mass flexible rotors as depicted by transfer matrix representation.

An extension of Prohl's (1945) critical speed method is employed (Lund, 1974; Bansal and Kirk, 1975) to determine the complex eigenvalues of the system dynamic matrix. The concept of logarithmic decrement, more easily understood, is applied to evaluate the degree of stability or instabilty in such multimass system. From the real and imaginary part of the damped natural frequencies, the logarithmic decrement, $\delta$, could be determined by

$$
\delta=-\frac{2 \cdot \pi \cdot P}{\omega_{d}}
$$

The log decrement is a powerful measure of the degree of stability and is a single parameter, which may be used to rank various design alternatives with respect to instability.

The analytical tools can be used to perform a rigorous stability analysis of a rotor-bearing system during the design stage thereby reducing the possibility of stability problem; it also can be used for problem diagnostics. It is to be realized that the application of this analytical tool effectively requires individual experience associated with the numbers generated from the analytical tool over a period of time.

\section{CASE STUDIES}

The following are presented case studies related to stability problem diagnostics, and design for stability of high-speed turbomachinery.

\section{Bearing Instability in a Turbocharger (Pettinato and De Choudhury, 2001)}

This case study presents the rotordynamic upgrade of a highspeed turbocharger used on diesel locomotives by a major world railroad. There were other mechanical design problems associated with the unit, however, only the part dealing with the rotordynamic stability problem is addressed here. The original turbocharger was supported by three-axial groove journal bearings. These bearings were changed to a three-lobe design in the modified turbocharger. The details of the existing and modified bearing geometries are listed in Table 1 .
Table 2 presents a rotordynamic summary consisting of the existing unit and modified unit. It was required that the upgraded unit keep the same footprint as the original. The overall length of the turbocharger was kept the same, but with a slight reduction in bearing span from $136 \mathrm{~mm}$ to $134 \mathrm{~mm}$. The total weight of the turbocharger was increased slightly from $30.6 \mathrm{~kg}$ to $33.0 \mathrm{~kg}$, due to a larger shaft collar and increased journal diameter at the turbine end. Peak responses at low speed were predicted for both the original and modified turbochargers. The low-speed peak responses related to the original turbocharger on three-axial-groove journal bearings had considerably higher amplification factor than the peak response associated with the modified turbocharger on three-lobe journal bearings.

As shown, the stiff support critical speeds were well above the maximum operating speed of $20,799 \mathrm{rpm}$. The rotor dynamics of both units would therefore be highly dependent on the bearing characteristics. Bearing dynamic coefficients are shown in Figures 1 through 4 for both sets of journal bearings (Lund, 1968). Examining the principal stiffness, as shown in Figure 1, indicates that the three-lobe bearing had higher asymmetry than the three-axial-groove bearing. As expected, the cross-coupled stiffness coefficients in Figure 2 were considerably less for the three-lobe journal bearing as compared to the three-axial-groove journal bearing. The principal damping coefficients, shown in Figure 3, were also less for the three-lobe bearing than for the three-axial-groove bearing. However, the significant decrease in cross-coupled stiffness of the three-lobe design resulted in improved stability. The predicted log decrement of the original unit with three-axial-groove journal bearing at maximum speed of 20,799 was -1.946 indicating a highly unstable rotor. However, the predicted log decrement of the modified turbocharger with three-lobe journal bearing was 0.394 , indicating a stable rotor. The rotor stability of the two units is presented in Figure 5, showing log decrement as a function of speed.

Vibration data from the test conducted of the original and the modified unit verified the rotordynamic predictions. The cascade diagram of the original turbocharger during run-up showed subsynchronous vibration on the unit at low-speed during start-up, dropping out over 3,000 rpm. Sub-synchronous vibration was again observed at 7,700 rpm and remained fairly steady with an increase in speed, while the synchronous vibration climbed with speed. At 16,500 rpm, the sub-synchronous vibration dropped out; however, the synchronous vibration increased rapidly and

TABLE 1

Bearing Geometries

\begin{tabular}{lcclcc}
\hline \multirow{2}{*}{ Items } & \multicolumn{2}{c}{ Existing: three-axial groove bearing } & & \multicolumn{2}{c}{ Modified: three lobe bearing } \\
\cline { 2 - 3 } & Turbine end & Compressor end & & Turbine end & Compressor end \\
\hline Journal diameter, D $(\mathrm{mm})$ & 47.52 & 47.52 & & 60.21 & 47.52 \\
Bearing length, L $(\mathrm{mm})$ & 21.0 & 21.0 & & 21.0 & 21.0 \\
Min. dia. clearance $(\mathrm{mm}) /$ preload & $0.08255 / 0.0$ & $0.08255 / 0.0$ & & $0.09017 / 0.85$ & $0.06985 / 0.87$ \\
Nom. dia. clearance $(\mathrm{mm}) /$ preload & $0.1079 / 0.0$ & $0.1079 / 0.0$ & & $0.1156 / 0.801$ & $0.09525 / 0.81$ \\
Max. dia. clearance $(\mathrm{mm}) /$ preload & $0.1334 / 0.0$ & $0.1334 / 0.0$ & & $0.1410 / 0.76$ & $0.1207 / 0.75$ \\
\hline
\end{tabular}


TABLE 2

Rotordynamic Analysis Results-Comparison of Original and Modified Turbochargers

\begin{tabular}{|c|c|c|c|c|}
\hline Parameters & \multicolumn{2}{|c|}{$\begin{array}{l}\text { Original turbocharger on } \\
\text { three-axial-groove bearings }\end{array}$} & \multicolumn{2}{|c|}{$\begin{array}{l}\text { Modified turbocharge } \\
\text { three-lobe bearings }\end{array}$} \\
\hline \multicolumn{5}{|l|}{ Rigid support critical speeds: } \\
\hline $1 \mathrm{st}$ & \multicolumn{2}{|c|}{45021} & \multicolumn{2}{|r|}{44665} \\
\hline 2nd & \multicolumn{2}{|c|}{129662} & \multicolumn{2}{|c|}{139361} \\
\hline Bearing span & \multicolumn{2}{|c|}{$136 \mathrm{~mm}$} & \multicolumn{2}{|c|}{$134 \mathrm{~mm}$} \\
\hline Overall length & \multicolumn{2}{|c|}{$396 \mathrm{~mm}$} & \multicolumn{2}{|c|}{$396 \mathrm{~mm}$} \\
\hline Total rotor weight & \multicolumn{2}{|c|}{$30.6 \mathrm{~kg}$} & \multicolumn{2}{|c|}{$33.0 \mathrm{~kg}$} \\
\hline \multicolumn{5}{|l|}{ Unbalance response: } \\
\hline & \multicolumn{2}{|c|}{ Peak response (AF) } & \multicolumn{2}{|c|}{ Peak response (AF) } \\
\hline & $\begin{array}{l}\text { Turbine end } \\
\text { bearing }\end{array}$ & $\begin{array}{l}\text { Compr. end } \\
\text { bearing }\end{array}$ & $\begin{array}{l}\text { Turbine end } \\
\text { bearing }\end{array}$ & $\begin{array}{l}\text { Compr. end } \\
\text { bearing }\end{array}$ \\
\hline $\begin{array}{l}\text { Out-of-phase unbalances } \\
\text { at ends }\end{array}$ & $\begin{array}{c}2350 \mathrm{rpm} \\
(16.7)\end{array}$ & $\begin{array}{l}2350 \mathrm{rpm} \\
(16.9)\end{array}$ & $\begin{array}{l}1200 \mathrm{rpm} \\
(2.35)\end{array}$ & $\begin{array}{c}1400 \mathrm{rpm} \\
(5.24)\end{array}$ \\
\hline \multirow[t]{2}{*}{$\begin{array}{l}\text { In-phase unbalances } \\
\text { at ends }\end{array}$} & $\begin{array}{l}8800 \mathrm{rpm} \\
(<1.0)\end{array}$ & - & - & $\begin{array}{c}7800 \mathrm{rpm} \\
(<1.0)\end{array}$ \\
\hline & - & - & $\begin{array}{l}19200 \mathrm{rpm} \\
(1.20)\end{array}$ & $\begin{array}{l}19000 \\
(<1.0)\end{array}$ \\
\hline $\begin{array}{l}\text { Stability log dec at } \\
20,799 \mathrm{rpm}\end{array}$ & \multicolumn{2}{|c|}{-1.946} & \multicolumn{2}{|c|}{0.394} \\
\hline
\end{tabular}

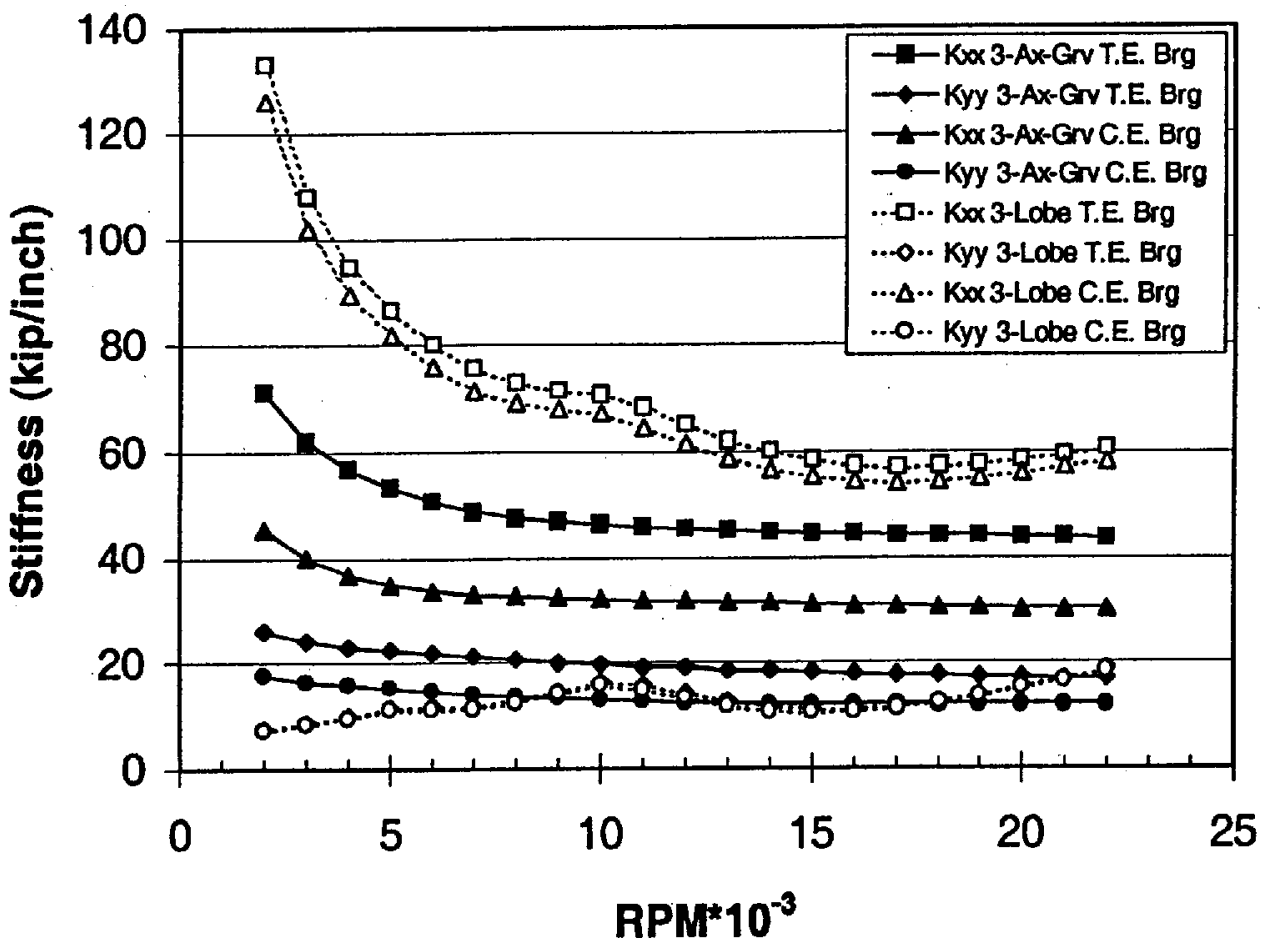

FIGURE 1

Bearing principal stiffness (kip/in $=175.1 \mathrm{~N} / \mathrm{mm}$ ). 


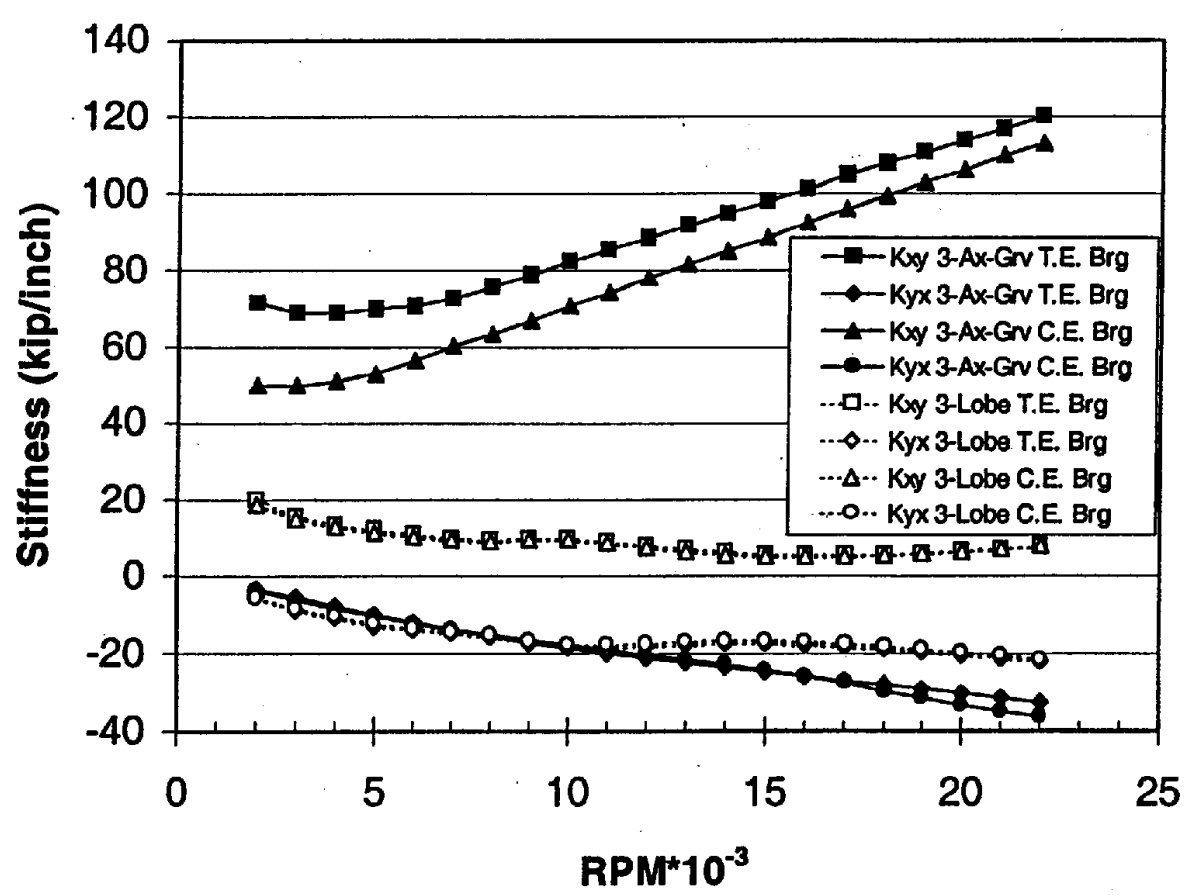

FIGURE 2

Bearing cross-coupled stiffness $(\mathrm{kip} / \mathrm{in}=175.1 \mathrm{~N} / \mathrm{mm})$.

reached $315 \mu \mathrm{m}$ at 19,500 rpm. At this speed, multiple frequencies of vibration were present, and it was determined that a rub had occurred. Disassembly of the unit showed that rub had occurred on the thrust bearing.
The cascade diagram, of the modified turbocharger with three lobe journal bearings, is presented in Figure 6. The unit was run up to $20,000 \mathrm{rpm}$. Sub-synchronous vibration was of low amplitude, $11.4 \mu \mathrm{m}$ at the compressor nose occurring beyond

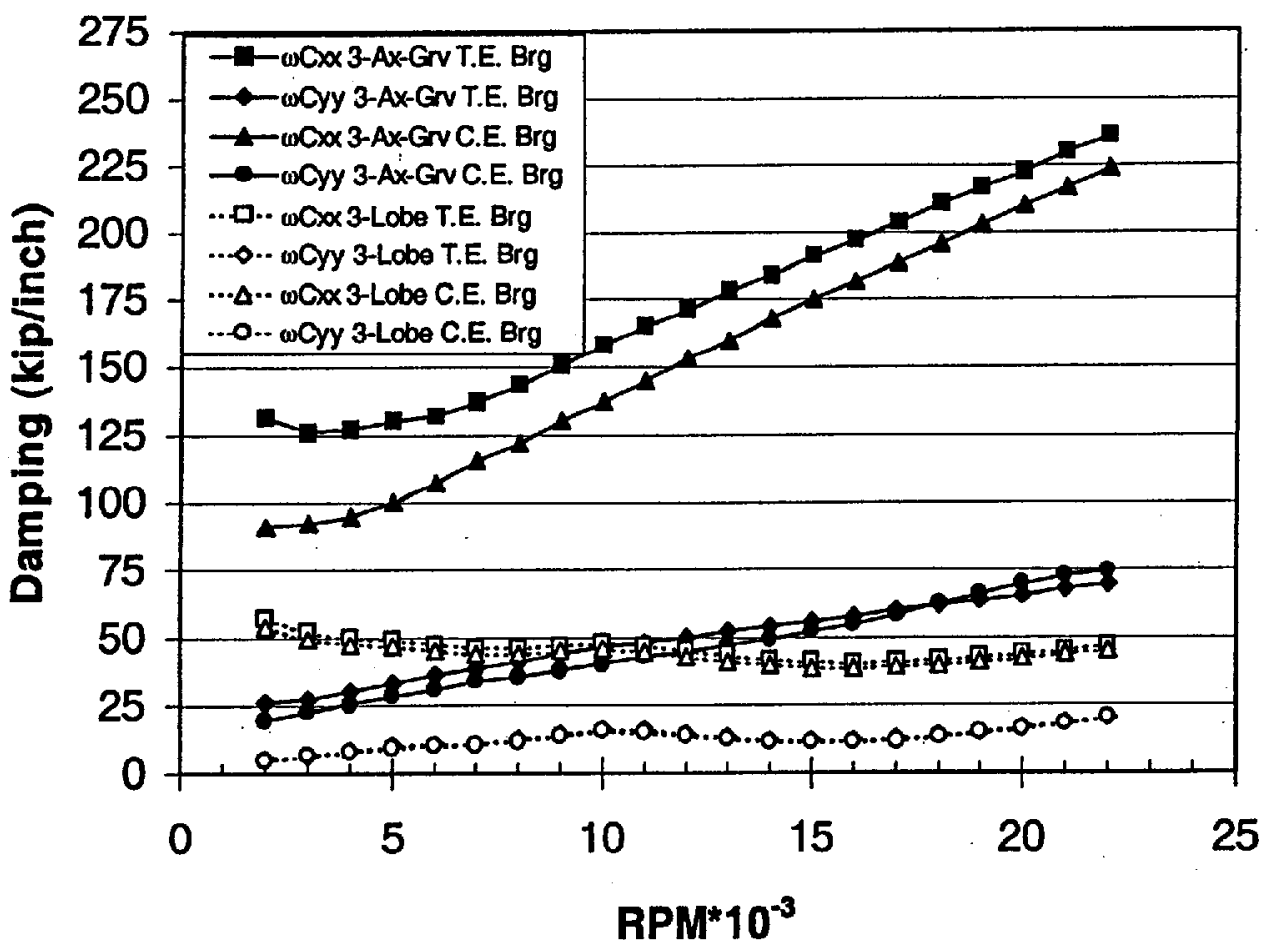

FIGURE 3

Bearing principal damping $(\mathrm{kip} / \mathrm{in}=175.1 \mathrm{~N} / \mathrm{mm})$. 


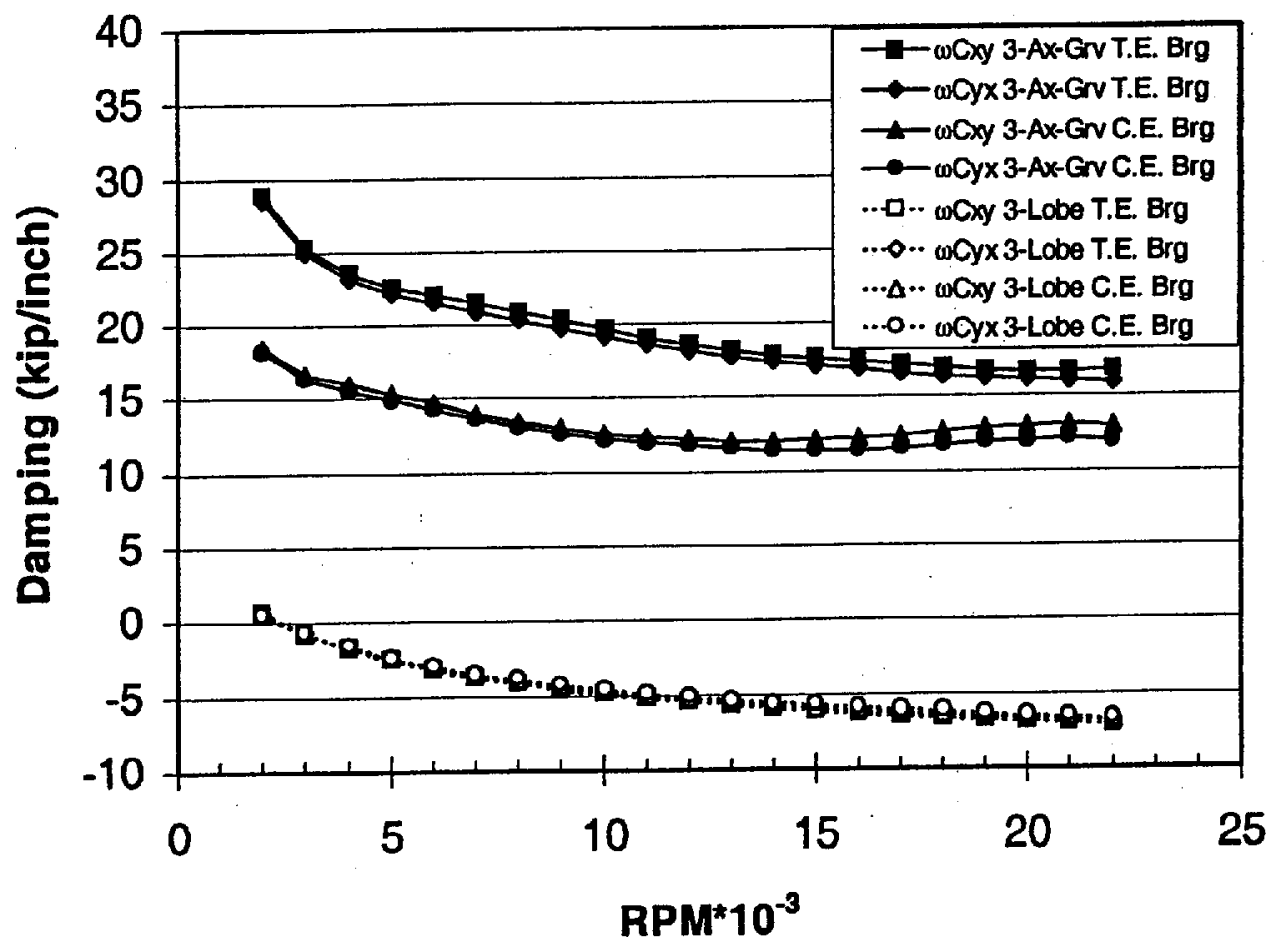

FIGURE 4

Bearing cross-coupled damping (kip/in $=175.1 \mathrm{~N} / \mathrm{mm})$.

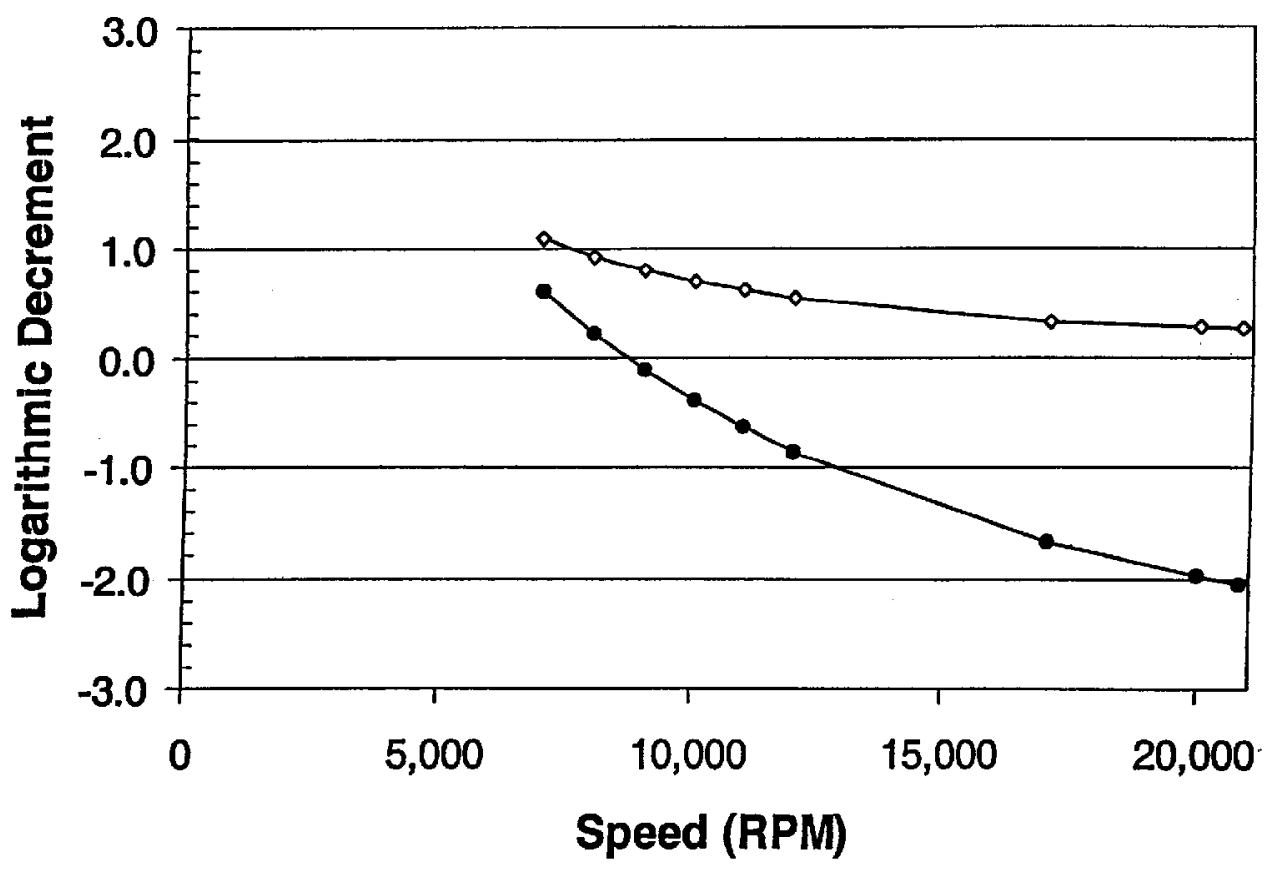

$\rightarrow-$ Original turbocharger with three-axial-groove Journal bearings $\therefore-$ Modified turbocharger with three-lobe bearings

FIGURE 5

Logarithmic decrement vs. speed. 


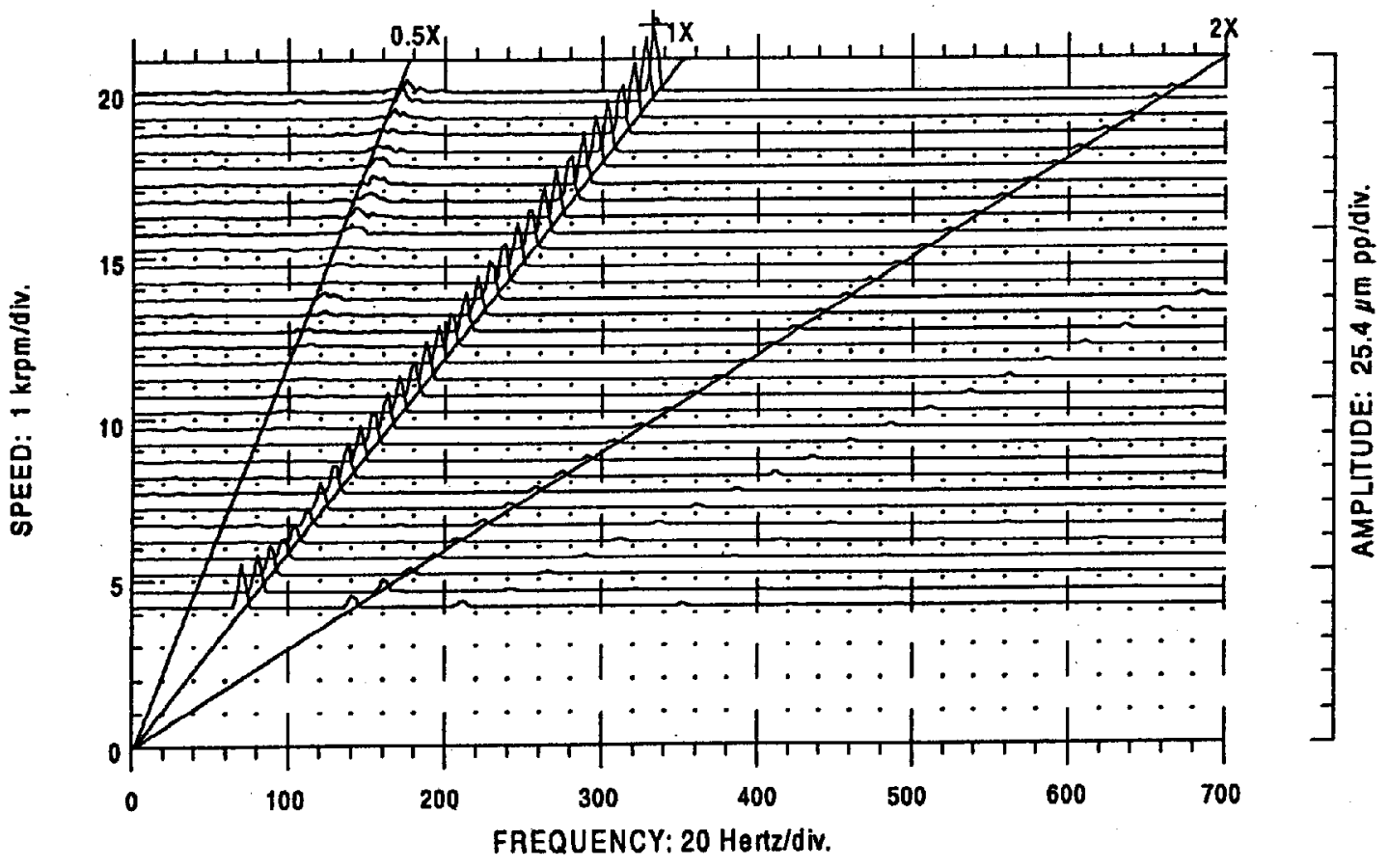

FIGURE 6

Cascade diagram, modified turbocharger at compressor nose piece.

$6,200 \mathrm{rpm}$. The synchronous vibration generally increased with speed, reaching a maximum of $48 \mu \mathrm{m}$ at $20,000 \mathrm{rpm}$, which was a considerable improvement over the original design.

\section{Centrifugal Compressor Instability Due to Aerodynamic Effect}

The instability problem is related to an eight-stage, backto-back compressor. The compressor speed range was 7,394 to $11,372 \mathrm{rpm}$. The inlet and discharge gas pressures were $12.5 \mathrm{~N} /$ $\mathrm{mm}^{2}$ and $23.0 \mathrm{~N} / \mathrm{mm}^{2}$, respectively. The average gas density of section 1 of the compressor was $33.56 \mathrm{~kg} / \mathrm{m}^{3}$, and that of section 2 was $65.0 \mathrm{~kg} / \mathrm{m}^{3}$. The compressor was supported by two five-shoe tilting pad journal bearings of load between pads configuration. The bearing diameter was $127 \mathrm{~mm}$. The shoes were $38.1 \mathrm{~mm}$ long and were a center pivot design. The preload and clearance data is shown in Table 3. The tilting pad journal bearings were analyzed using frequency dependent methods (Smalley et al., 1975).

TABLE 3

Journal Bearing Preload and Clearance

\begin{tabular}{lcc}
\hline $\begin{array}{c}\text { Bearing } \\
\text { preload }\end{array}$ & $\begin{array}{c}\text { Pad diametral } \\
\text { machined clearance } \\
(\mathrm{mm})\end{array}$ & $\begin{array}{c}\text { Bearing assembled } \\
\text { diametral clearance } \\
(\mathrm{mm})\end{array}$ \\
\hline 0.391 & 0.2921 & 0.1778 \\
0.489 & 0.29845 & 0.1524 \\
0.583 & 0.3048 & 0.1270 \\
\hline
\end{tabular}

The as-designed bearing span was $1930.4 \mathrm{~mm}$ and the first stiff support critical speed was 3,976 rpm. The flexibility ratio, defined as the ratio of maximum continuous speed to first rigid support critical speed, was 2.76 . The flexibility ratio gives a qualitative indication of rotor susceptibility to stability problem (Sood, 1979). The higher the flexibility ratio, the greater the possibility that the rotor may go unstable. Other factors such as gas pressure and gas density also play major roles in destabilizing the rotor.

Whereas rotordynamic stability analysis is routinely performed today, the rotor in question was designed and manufactured at a time when such analysis was simply not done. The machine was shipped and started. It had stability problems at maximum continuous speed and at certain operating conditions, resulting in sub-synchronous vibration at a frequency corresponding to first critical speed. One way that stability could be improved in this rotor-bearing system was to reduce the bearing span, as practically as possible. This would increase the first rigid support critical, thus making the rotor less flexible. After several iterative rotordynamic studies, it was perceived that the bearing span could be reduced to $1742 \mathrm{~mm}$. Additional stiffening of the shaft was obtained through increasing the main shaft diameter from 159 to $165.1 \mathrm{~mm}$, raising the first rigid support critical speed to $5,155 \mathrm{rpm}$ and reducing the corresponding flexibility ratio to 2.16 .

Table 4 shows a comparison of the as-designed rotor bearing system and the modified system. Sensitivity of the rotordynamic stability due to aerodynamic cross-coupling stiffnesses applied at the compressor impellers are also shown. The estimated 
TABLE 4

Log Decrements at 11,372 rpm

\begin{tabular}{|c|c|c|c|c|c|c|}
\hline \multirow[b]{2}{*}{ Aero CC N/mm } & \multicolumn{3}{|c|}{ As designed $159 \mathrm{~mm}$ shaft diameter } & \multicolumn{3}{|c|}{ Modified shaft $165.1 \mathrm{~mm}$ shaft diameter } \\
\hline & $\begin{array}{c}\text { Min. } \\
\text { clearance }\end{array}$ & $\begin{array}{c}\text { Avg. } \\
\text { clearance }\end{array}$ & $\begin{array}{c}\text { Max. } \\
\text { clearance }\end{array}$ & $\begin{array}{c}\text { Min. } \\
\text { clearance }\end{array}$ & $\begin{array}{c}\text { Avg. } \\
\text { clearance }\end{array}$ & $\begin{array}{c}\text { Max. } \\
\text { clearance }\end{array}$ \\
\hline 0 & 0.074 & 0.118 & 0.143 & 0.144 & 0.209 & 0.262 \\
\hline 175 & -0.001 & 0.048 & 0.100 & 0.101 & 0.173 & 0.239 \\
\hline 350 & -0.078 & -0.033 & 0.023 & 0.056 & 0.128 & 0.203 \\
\hline 525 & -0.154 & -0.117 & -0.074 & 0.010 & 0.078 & 0.149 \\
\hline 700 & -0.231 & -0.200 & -0.169 & -0.036 & 0.027 & 0.090 \\
\hline Estimated aero $\mathrm{CC}$ & -0.246 & -0.216 & -0.186 & -0.001 & 0.067 & 0.137 \\
\hline \multicolumn{7}{|c|}{ Rigid support critical speeds } \\
\hline $1 \mathrm{st}$ & & 3976 & & & 5155 & \\
\hline $2 \mathrm{nd}$ & & 15978 & & & 18457 & \\
\hline Flex ratio & & 2.79 & & & 2.16 & \\
\hline \multicolumn{7}{|c|}{ Estimated aero cross-coupling } \\
\hline At stages & & $635 \mathrm{~N} / \mathrm{mm}$ & & & $490 \mathrm{~N} / \mathrm{mm}$ & \\
\hline At balance piston & & $1195 \mathrm{~N} / \mathrm{mm}$ & & & $922 \mathrm{~N} / \mathrm{mm}$ & \\
\hline Bearing span & & $1930.4 \mathrm{~mm}$ & & & $1742.0 \mathrm{~mm}$ & \\
\hline
\end{tabular}

cross-coupling was calculated using the compressor OEM's empirical equation of the form:

$$
Q=\beta * f\left(P_{i}, T_{i}, P_{d}, T_{d}, M_{w}, N_{\max }, N_{r 1}\right)
$$

The above formula was developed at the speed, and the operating conditions at which the compressors went unstable. Aerodynamic cross-coupling stiffness coefficients were applied at the impeller locations until the log decrement became zero, indicating threshold of instability. The estimated cross-coupling stiffness is based on the inlet and discharge gas pressures $\left(P_{i}\right.$, $\left.P_{d}\right)$, the inlet and discharge gas temperatures $\left(T_{i}, T_{d}\right)$ of the compressor, the maximum operating speed $\left(N_{\max }\right)$, and the first rigid support critical speed $\left(N_{r 1}\right) . \beta$ is an empirical constant.

It can be noted that the as-designed rotor was much more sensitive to the destabilizing aerodynamic cross-coupling stiffnesses than the modified rotor. The modified rotor did not have any stability problem in the field and is operating trouble free.

\section{Instability Due to Oil Seals}

This example presents a field problem involving a sixstage moderate pressure, high-speed compressor where the stability was improved by application of an optimized fiveshoe tilt-pad bearing, and modified oil seals. The unit operated with inlet and discharge pressures of 1.04 and $4.52 \mathrm{~N} / \mathrm{mm}^{2}$, respectively; inlet and discharge gas densities were 7.53 and $24.4 \mathrm{~kg} / \mathrm{m}^{3}$, respectively. The compressor operating speed was $11,686 \mathrm{rpm}$, the bearing span was $1,709 \mathrm{~mm}$, and the first rigid support critical speed was $4,656 \mathrm{rpm}$. The flexibility ratio was thus 2.50 .
Table 5 shows the bearing geometry associated with the original five-shoe tilt-pad journal bearing, center pivot, load between pads configuration. The modified bearings were five-shoe tiltpad, offset pivot, load between pads configuration. The pad machined clearances were kept the same in the modified design, however, the preload was reduced for improved stability. This was achieved by increasing the assembled clearance by grinding the spherical seats pivots (Pettinato and De Choudhury, 1999). The tilting pad journal bearing were analyzed using frequencydependent methods (Smalley et al., 1975).

Figure 7 shows the sensitivity of the rotor bearing system with respect to aerodynamic cross-coupling stiffness at the impellers at the maximum continuous speed of 11,686 rpm. Results at minimum, average, and maximum bearing clearances are shown for the original bearings, and bearings with modified geometry. It is observed that the sensitivity of the rotor to aerodynamic cross-coupling stiffness coefficients is reduced

TABLE 5

Original and Modified Bearing Designs

\begin{tabular}{llcc}
\hline Bearing & Preload & $\begin{array}{c}\text { Pad machined } \\
\text { diametral } \\
\text { clearance }(\mathrm{mm})\end{array}$ & $\begin{array}{c}\text { Pad assembled } \\
\text { diametral } \\
\text { clearance }(\mathrm{mm})\end{array}$ \\
\hline Original bearing & 0.25 & .2032 & .1524 \\
Center pivot & 0.394 & .2096 & .1270 \\
Load between pads & 0.529 & .3159 & .1016 \\
Modified bearing & 0.10 & .2032 & .1829 \\
Offset pivot & 0.2485 & .2096 & .1575 \\
Load between pads & 0.3882 & .2159 & .1321 \\
\hline
\end{tabular}




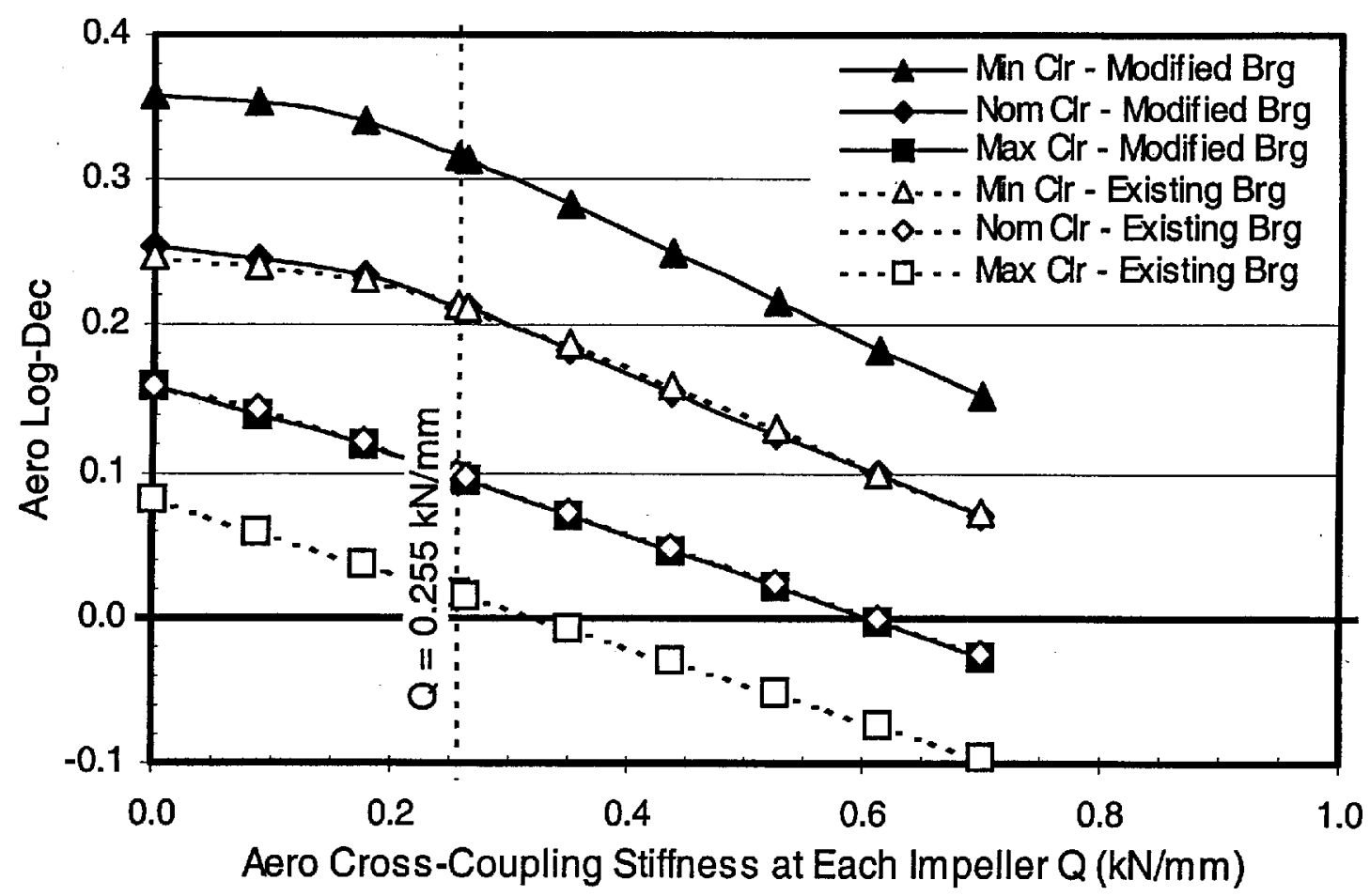

FIGURE 7

Compressor aero sensitivity.

using the modified bearing. Comparing the bearing designs, zero $\log$ decrement occurs at $315.2 \mathrm{~N} / \mathrm{mm} /$ impeller with as-designed bearings, whereas using the modified bearing design this increases to $595 \mathrm{~N} / \mathrm{mm} / \mathrm{impeller}$. The minimum clearance case for both bearing designs gives lower log decrements. Cross plot of the estimated aerodynamic cross-coupling stiffness shows that at minimum clearance the rotor bearing system could be marginally stable with the original bearing.

The effect of oil seals (Newkirk and Taylor, 1925) on the stability was evaluated next to improve the rotor stability. The results of the analysis are presented in Table 6 , at the minimum bearing clearance of the modified journal bearing. The worstcase condition is presented in Table 6, at original seal radial clearance of $0.0889 \mathrm{~mm}$, with no grooves in the seals, and at $0.1143 \mathrm{~mm}$ radial clearance with one groove. The pressure differential across the oil seal was $0.3498 \mathrm{~N} / \mathrm{mm}^{2}$. The effect of the estimated aerodynamic cross-coupling stiffness coefficient of $0.255 \mathrm{kN} / \mathrm{mm} / \mathrm{impeller}$ is included in the analysis. It is observed

TABLE 6

Effect of Oil Seals on Log Decrements at 11,500 rpm

\begin{tabular}{lcc}
\hline $\begin{array}{l}\text { Oil seal radial } \\
\text { clearance }(\mathrm{mm})\end{array}$ & $\begin{array}{c}\text { No groove in } \\
\text { the oil seal }\end{array}$ & $\begin{array}{c}\text { One groove } \\
1.59 \mathrm{~mm} \times 1.59 \mathrm{~mm} \\
\text { in oil seal }\end{array}$ \\
\hline 0.0889 & 0.075 & 0.079 \\
0.1143 & 0.106 & 0.120 \\
\hline
\end{tabular}

that an increase in seal radial clearance along with one groove improves the stability at the operating speed and conditions. The unit was provided with modified bearings and increased oil seal clearance. These modifications were sufficient to stabilize the rotor.

\section{CONCLUSIONS}

- In the past, the design of turbomachinery relied on overly conservative designs. The economics of the turbomachinery industry, however, forced the application of high-pressure designs, increased number of stages, and increased rotor flexibility. This resulted in a number of field problems and the required adaptation of rotordynamic stability analysis.

- Practical analytical methods are available to analyze stability related problems.

- This article shows how some significant stability problems associated with high-speed turbomachinery have been analyzed for problem resolution and design purposes using the available analytical tools.

- Empirical criteria developed over years of experience by turbomachinery manufacturers continue to evolve such that the application of analytical results can be correctly applied.

\section{ACKNOWLEDGMENTS}

The author is indebted to the Elliott Company for permission to publish this article and to the many individuals within 
the company whose support and assistance made this work possible.

\section{REFERENCES}

Alford, J. S. 1965. Protecting turbomachinery from self-excited rotor whirl. Journal of Engineering for Power, Transactions of the ASME, Series A 4:333-344.

Bansal, P. N., and Kirk, R. G. 1975. Stability and damped critical speeds of rotor-bearing system. Journal of Engineering for Industry 13251332.

Boeker, G. F., and Sternlicht, B. 1956. Investigation of translatory fluid whirl in vertical machines. Transactions of the ASME 13-19.

De Choudhury, P. 2001. Application of lund's stability analysis program in design of modern turbomachinery. Proceedings of DET01, Paper No. VIB21374.

Gunter, E. J., Jr. 1966. Dynamic stability of rotor-bearing systems. NASA SP-113.

Kirk, R. G., and Miller, W. H. 1979. The influence of high pressure oil seals on turbo-rotor stability. ASLE Transactions 22(1):14 24.

Lund, J. W. 1968. Rotor-bearing dynamics design technology, part VII: The three lobe bearing and floating ring bearing, Technical Report AFAPL-TR-65-45, PART VII, Air Force Aero Propulsion Laboratory, Wright-Patterson Air Force Base, Ohio.

Lund, J. W. 1974. Stability and damped critical speeds of a flexible rotor in fluid film bearings. Journal of Engineering for Industry 509517.
Newkirk, B. L., and Lewis, J. F. 1956. Oil-film whirl—an investigation of disturbances due to oil films in journal bearings. Trans. of the ASME 78:21-27.

Newkirk, B. L., and Taylor, H. D. 1925. Shaft whipping due to oil action in journal bearings. General Electric Review 559-568.

Pettinato, B., and De Choudhury, P. 1999. Test results of key and spherical pivot five-shoe tilt pad journal bearings-part I: Performance measurements. Tribology Transactions 42:541-547.

Pettinato, B., and De Choudhury, P. 2001. Rotordynamic and bearing upgrade of a high-speed turbocharger. Proceedings of ASME TURBO EXPO 2001, June 4-7, New Orlean.

Poritsky, H. Rotor-bearing dynamics design technology, Part II: Rotor stability theory. Technical Report AFAPL-TR-65-45.

Prohl, M. A. 1945. A general method for calculating critical speeds of flexible rotors. Journal of Applied Mechanics.

Reddi, M. M., and Trumpler, P. R. 1962. Stability of high speed journal bearings under steady load-1. The compressible film. Journal of Engineering for Industry, Transactions of the ASME, Series B 84:351-358.

Smalley, A. J., Almstead, L. G., Lund, J. W., and Koch, E. S. 1975. User's manual: MTI cadense program CAD-25, Mechanical Technologies Incorporated, Latham, NY.

Sood, V. K. 1979. Design and full load testing of a centrifugal natural gas injection compressor. Proceedings of the Eighth Turbomachinery Symposium 35-42.

Wachel, J. C. 1982. Rotordynamic instability problems. Proceedings of Rotordynamic Instability Problems in High-Performance Turbomachinery, NASA CP-2250, 1-19. 

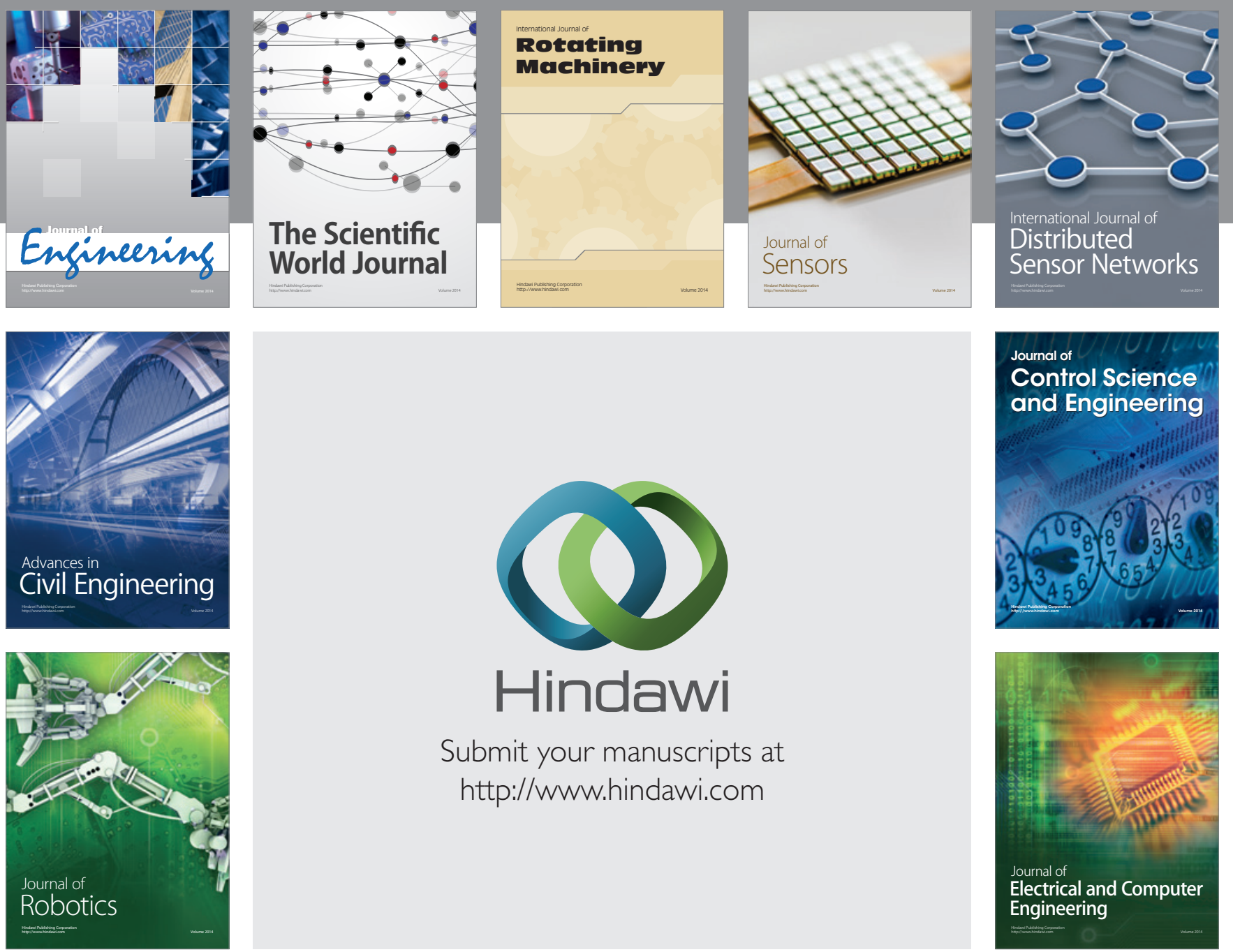

Submit your manuscripts at

http://www.hindawi.com
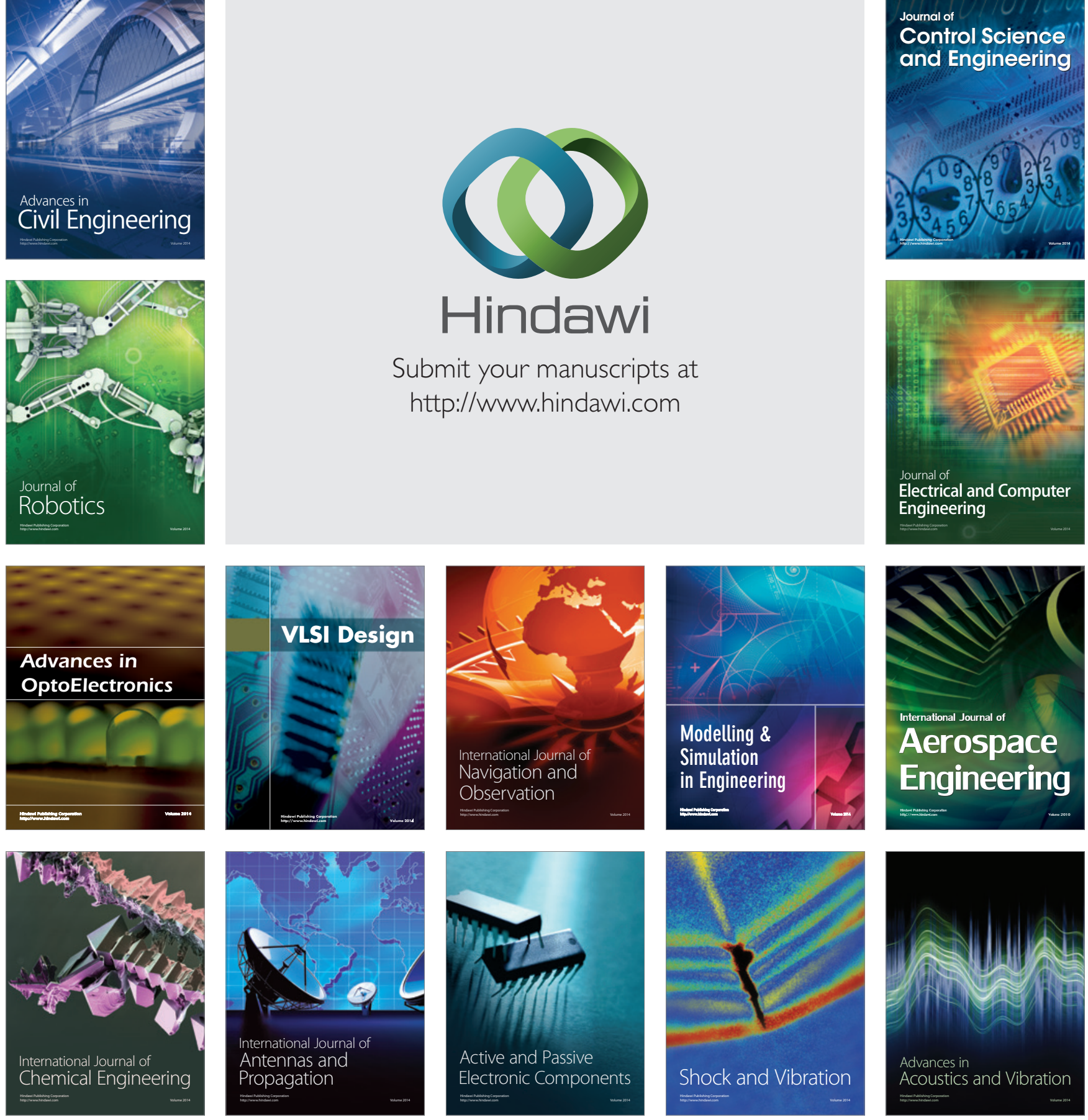